Dermatology 2008;216:347-348

DOI: $10.1159 / 000116622$

\section{Age at Diagnosis of Neurofibromatosis 1: An Audit of Practice}

S. Abecassis ${ }^{\text {a }}$, S. Bastuji-Garin ${ }^{\text {b }}$, K. Khosrotehrani ${ }^{\text {a }}$, J. Zeller ${ }^{\text {a }}$,

Departments of a Dermatology and ${ }^{b}$ Public Health, Hôpital Henri-Mondor, Assistance Publique - Hôpitaux de Paris, Université Paris-XII, Créteil, France

\section{Key Words}

Neurofibromatosis $1 \cdot$ Age at diagnosis

Neurofibromatosis 1 (NF1) is a common genetic disease with an incidence of about 1 in 2,500 [1, 2], an autosomal dominant mode of inheritance and a high rate of new mutations. Two striking aspects of NF1 are its progression with age and its extreme variability [2]. Its diagnosis is based on 7 criteria of which 2 are required for diagnosis: $\geq 6$ significant café-au-lait macules (CLM), $\geq 2$ neurofibromas of any type or 1 plexiform neurofibroma, freckling in the axillary or inguinal regions, optic glioma, $\geq 2$ Lisch nodules, a distinctive osseous lesion such as sphenoid dysplasia or thinning of the long bone cortex with or without pseudarthrosis, a first-degree relative with NF1. Although specificity and sensitivity of these criteria are high during adulthood, their sensitivity is low during early childhood: $97 \%$ of NF1 patients meet them by the age of 8 years, but only $70 \%$ by the age of 1 year [3]. In France, the diagnosis is often made in young adults, and the detection of the early complications needs precocious diagnosis [4]. We conducted a retrospective audit of practice to identify features associated with early diagnosis.

\section{Methods}

We prospectively ascertained 433 patients with NF1 between 1995 and 2001 using the National Neurofibromatosis Foundation International Database Software (Vancouver, B.C., Canada) [5], counting only 41 children ( $<17$ years old) since our clinic is a referral centre for adults. Patients were systematically asked for their age when the diagnosis was made, and excluded if the answer was not available.

We performed a cross-sectional analysis. The median age at diagnosis (13 years) served arbitrarily as the limit between two groups of patients: patients with an age at diagnosis $\leq 13$ years were classified in group 1 (early diagnosis group) and patients with a diagnosis age $>13$ years in group 2 (delayed diagnosis group). Features present after supposed full penetrance (age of 8 years) and before the median age at diagnosis were included in the analysis.

Univariate analysis compared features between groups 1 and 2 (table 1). Odds ratios (OR) with 95\% confidence intervals (CI) were calculated separately for each variable using unconditional logistic regression models. Factors were selected for inclusion in the multivariate model by using multiple $2 \times 2$ analyses on variables that emerged from the univariate analysis $(\mathrm{p}<0.15)$; interaction and confounding were assessed by fitting multiplicative models, then we conducted a backward step-by-step logistic regression. $\mathrm{p} \leq 0.05$ indicated statistical significance. All significance tests were 2-tailed. We also compared the age at diagnosis of NF1 and the year of birth by using the Kruskal-Wallis test.

\section{Results}

Three-hundred seventy patients were included. Their mean age was $32.7 \pm 13.5$ years. The mean age at NF1 diagnosis was $14.9 \pm 12.9$ years (median: 13 years). The mean time between the diagnosis and the first consultation was $17.52 \pm 12.45$ years. Table 1 summarizes their characteristics and the comparison between features of groups 1 and 2 .

After multivariate analysis, features of NF1 independently associated with early diagnosis were: presence of at least 6 CLM $\geq 15$ $\mathrm{mm}(\mathrm{OR}=1.62,95 \% \mathrm{CI}=1.01-2.60, \mathrm{p}=0.047)$, at least 10 cutaneous neurofibromas (10-99 cutaneous neurofibromas, $\mathrm{OR}=0.36$, $95 \% \mathrm{CI}=0.17-0.66, \mathrm{p}=0.002$; over 100 neurofibromas, $\mathrm{OR}=0.35$, $95 \% \mathrm{CI}=0.18-0.71, \mathrm{p}=0.003)$, at least 1 plexiform neurofibroma $(\mathrm{OR}=2.06,95 \% \mathrm{CI}=1.30-3.28, \mathrm{p}=0.002)$ and facial asymmetry $(\mathrm{OR}=3.49,95 \% \mathrm{CI}=1.42-8.55, \mathrm{p}=0.006)$.

The average age at diagnosis decreased over the years (fig. 1; $\mathrm{p}<0.0001)$.

\section{Comments}

As expected, patients with the most visible phenotypes were diagnosed earlier in childhood. Facial asymmetry and plexiform neurofibromas are generally apparent during the first years of life.

However, many NF1 patients still remain undiagnosed long after the disease has reached full penetrance: the median age of

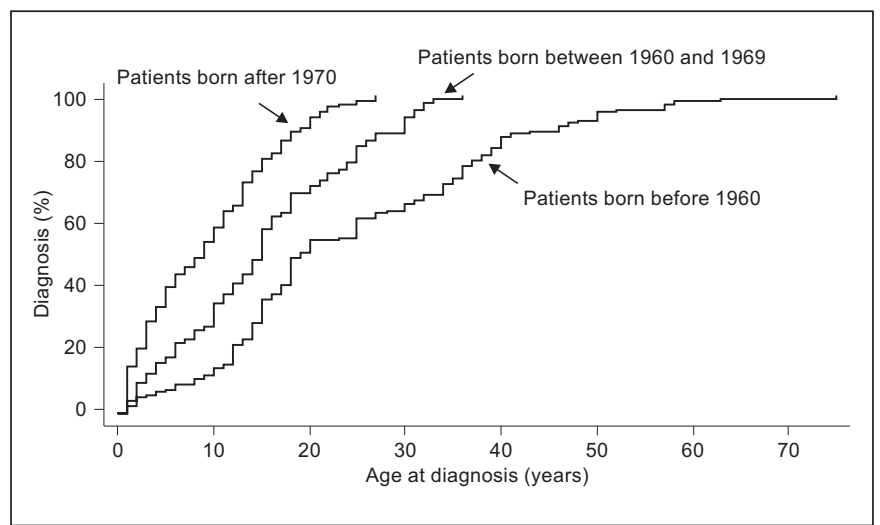

Fig. 1. Year of birth and age at diagnosis of NF1: the age at NF1 diagnosis decreased over the years (Kruskall-Wallis test; $\mathrm{p}<$ 0.0001).

\section{KARGER}

(ㄷ) 2008 S. Karger AG, Basel

Fax +41613061234 E-Mail karger@karger.ch www.karger.com 
Table 1. Comparison of features of 370 patients with early or delayed diagnosis of NF1 (univariate analysis)

\begin{tabular}{|c|c|c|c|c|c|c|c|}
\hline Clinical features & $\begin{array}{l}\text { Missing } \\
\text { data }\end{array}$ & $\begin{array}{l}\text { Patients presenting } \\
\text { each clinical feature }\end{array}$ & $\begin{array}{l}\text { Patients with } \\
\text { early diagnosis } \\
(\mathrm{n}=191)\end{array}$ & $\begin{array}{l}\text { Patients with } \\
\text { delayed diagnosis } \\
(\mathrm{n}=179)\end{array}$ & $\mathrm{p}$ & OR & $95 \% \mathrm{CI}$ \\
\hline Familial history of NF1 & 0 & $143(38.65)$ & $73(38.22)$ & $70(39.11)$ & 0.861 & 0.96 & $0.63-1.46$ \\
\hline$\geq 6$ CLM $\geq 15 \mathrm{~mm}$ & 0 & $250(67.57)$ & $138(72.35)$ & $112(62.57)$ & 0.047 & 1.56 & $1.00-2.41$ \\
\hline$\geq 6 \mathrm{CLM} \geq 5 \mathrm{~mm}$ & 0 & $274(74.05)$ & $147(76.96)$ & $127(70.95)$ & 0.188 & 1.37 & $0.86-2.18$ \\
\hline \multicolumn{8}{|l|}{ Freckling } \\
\hline Axillary & 0 & $327(88.38)$ & $168(87.96)$ & $159(88.83)$ & 0.794 & 0.92 & $0.48-1.73$ \\
\hline Diffuse & 0 & $187(50.54)$ & $93(48.69)$ & $94(52.51)$ & 0.462 & 0.86 & $0.57-1.29$ \\
\hline \multicolumn{8}{|l|}{ Cutaneous neurofibromas } \\
\hline Absent & & $59(16.53)$ & $20(11.43)$ & $39(21.43)$ & & 1 & \\
\hline $1-9$ & & $61(17.09)$ & $24(13.71)$ & $37(20.33)$ & 0.536 & 0.79 & $0.37-1.66$ \\
\hline $10-99$ & & $128(35.85)$ & $72(41.14)$ & $56(30.77)$ & 0.005 & 0.40 & $0.20-0.76$ \\
\hline$\geq 100$ & & $109(30.53)$ & $59(33.71)$ & $50(27.47)$ & 0.013 & 0.43 & $0.22-0.84$ \\
\hline Subcutaneous neurofibroma & 2 & $190(51.63)$ & $105(55.26)$ & $85(47.75)$ & 0.150 & 1.35 & $0.89-2.04$ \\
\hline Plexiform neurofibroma & 2 & $142(38.59)$ & $89(46.84)$ & $53(29.78)$ & 0.001 & 2.08 & $1.35-3.19$ \\
\hline Facial asymmetry & 0 & $33(8.92)$ & $26(13.61)$ & $7(3.91)$ & 0.002 & 3.87 & $1.64-9.16$ \\
\hline Macrocephaly & 87 & $35(12.4)$ & $21(14.8)$ & $14(9.9)$ & 0.157 & 1.70 & $0.80-3.61$ \\
\hline Pseudarthrosis & 1 & $7(1.90)$ & $3(1.58)$ & $4(2.23)$ & 0.646 & 0.70 & $0.15-3.18$ \\
\hline Congenital tibial bowing & 2 & $8(2.17)$ & $5(2.65)$ & $3(1.68)$ & 0.527 & 1.59 & $0.37-6.77$ \\
\hline Scoliosis & 3 & $167(45.50)$ & $92(48.68)$ & $75(42.13)$ & 0.209 & 1.30 & $0.86-1.97$ \\
\hline Hydrocephalus & 2 & $8(2.17)$ & $7(3.70)$ & $1(0.56)$ & 0.073 & 6.84 & $0.83-56.21$ \\
\hline Optic pathway glioma & 8 & $36(9.94)$ & $24(12.97)$ & $12(6.78)$ & 0.053 & 2.05 & $0.99-4.24$ \\
\hline Lish nodules & 117 & $215(84.98)$ & $114(85.71)$ & $101(84.17)$ & 0.731 & 1.13 & $0.57-2.25$ \\
\hline Short stature & 20 & $45(12.9)$ & $24(13.3)$ & $21(12.4)$ & 0.60 & 1.10 & $0.61-1.89$ \\
\hline
\end{tabular}

$\mathrm{OR}=$ Odds ratios; $\mathrm{CI}=$ confidence intervals. Figures in parentheses indicate percentages.

diagnosis in our study was 13 . In our cohort, the age at NF1 diagnosis decreased over the years. This could be explained by an ascertainment bias or by a real improvement on the delay of NF1 diagnosis due to the publication of the NIH NF1 diagnosis criteria in 1987 and the creation of neurofibromatosis clinics.

Although $3 \mathrm{NIH}$ diagnosis criteria of NF1 are visible on the skin, these signs are often considered as common by patients, their families and their general practitioners. Subcutaneous neurofibromas often appear during childhood. Even though subcutaneous neurofibromas are linked to more severe cases [6], and are often symptomatic, they were not associated with early diagnosis in our study. Numerous neurofibromas and large CLM $(\geq 15$ $\mathrm{mm}$ ) were associated with early diagnosis, small CLM were not.

Interestingly, the criterion of having a first-degree relative with NF1 did not contribute to early diagnosis [7]. Genetic inquiry should be performed and should include the examination of all family members.

Rare complications of NF1 (skeletal abnormalities, gliomas and hydrocephalus) are often managed by a single specialist, without multidisciplinary approach. In our series, the presence of these complications was not associated with an early diagnosis, and previous studies found that major NF1 complications may be evident in children with a significant diagnosis delay [7]. Optic pathway glioma, pseudarthrosis, long bone bowing and sphenoid dysplasia are included in the NIH diagnostic criteria, and the second criterion necessary for the diagnosis is easy to find on the skin.

\section{References}

1 Lammert M, Friedman JM, Kluwe L, Mautner VF: Prevalence of neurofibromatosis 1 in German children at elementary school enrollment. Arch Dermatol 2005;141:71-74.

2 Friedman JM: Neurofibromatosis 1: clinical manifestations and diagnostic criteria. J Child Neurol 2002;17:548-554.

3 DeBella K, Szudek J, Friedman JM: Use of the National Institutes of Health criteria for diagnosis of neurofibromatosis 1 in children. Pediatrics 2000;105:608-614.

4 Cnossen MH, de Goede-Bolder A, van de Broek KM, et al: A prospective 10-year follow-up study of patients with neurofibromatosis type 1 . Arch Dis Child 1998;78:408-412.

5 Friedman JM, Birch P, Greene C: National Neurofibromatosis Foundation International Database. Am J Med Genet 1993;45:88-91.

6 Khosrotehrani K, Bastuji-Garin S, Zeller J, et al: Clinical risk factors for mortality in patients with neurofibromatosis 1 , a cohort study of 378 patients. Arch Dermatol 2003;139:187-191.

7 Cnossen MH, Smit FJ, de Goede-Bolder A, Frets PG, Duivenvoorden HJ, Niermeijer MF: Diagnostic delay in neurofibromatosis type 1. Eur J Pediatr 1997;156:482-487.

Pierre Wolkenstein, $\mathrm{MD}, \mathrm{PhD}$

Hôpital Henri-Mondor, Department of Dermatology

51, avenue du Maréchal-Delattre-de-Tassigny

FR-94010 Créteil Cedex (France)

Tel. +33149812536, Fax +33149812508

E-Mail pierre.wolkenstein@hmn.aphp.fr 